\title{
Unión Europea y Políticas de Igualdad (y Sexualidad) en España: entrevista con Raquel Platero
}

\author{
Rosa María Blanca \\ Universidade Federal de Santa Catarina
}

\begin{abstract}
Estamos investigando, dentro del Programa de Postgrado Interdisciplinar en Ciencias Humanas, en la Universidad Federal de Santa Catarina, Brasil, el arte erótico como objeto de estudios, desde una perspectiva queer. Se trata de un proyecto inserido en el área de Estudios de Género, orientado por Miriam Pillar Grossi, y coorientado por Claudia de Lima Costa. En el desarrollo de nuestra investigación, hemos percibido la importancia de documentos electrónicos Open Access e Internet como fuente de información. Durante el período que hemos permanecido en Madrid, España, con motivo de la realización de una práctica doctoral para comparar revistas electrónicas españolas y brasileñas, mediante un convenio Brasil-España, de CAPES/DGU, coordinado por Carmen Rial, hemos decidido entrevistar a Raquel Platero, activista por los derechos de Lesbianas, Gays, Transgéneros, Transexuales, Bisexuales y Queers (LGTBQ). Platero es también psicóloga e investigadora. Posee Master en Evaluación de Políticas y Programas. Actualmente es doctoranda del Programa de Perspectiva de Género en las Ciencias Sociales de la Universidad Complutense de Madrid, España. Obtuvo la Beca "Associate Fellow Scheme" en Research Center for Law, Gender and Sexuality, de la Universidad de Kent, en 2005. También ha trabajado en el Proyecto $/+D+/$, de la Universidad Autónoma de Madrid, sobre "Situación de las mujeres sordas respecto a su formación y posibilidades",
\end{abstract}

Copyright ๑ 2013 by Revista Estudos Feministas 
UNESCO. Como docente, ha actuado en el Postgrado de Género de la Universidad Pública de Navarra, en la asignatura de "Desigualdad de Género y Políticas de Igualdad", así como en el Master en Igualdad de Género: Formación de Agentes para la Igualdad, de la Universidad de Castilla la Mancha, en el Master en Estudios Feministas. Políticas de Igualdad y Violencia de Género, de la Universidad de Laguna, en el Master de Género y Desarrollo, en la asignatura "Marcos interpretativos de políica y metodología MAGEEQ", de la Universidad Complutense de Madrid - Instituto de la Mujer, entre otros muchos. La realización de la entrevista ha contribuido para la concretización de la investigación Centro de Documentación Electrónica, con apoyo de la Fundação do Amparo à Pesquisa do Rio Grande do Sul (FAPERGS). 
Rosa Blanca: ¿Cómo has podido conciliar un activismo en el movimiento LGBTQ y tu investigación académica?

Raquel Platero: Yo soy primeramente una persona que viene del activismo: estuve trabajando por los derechos de las personas jóvenes, a finales de los 80's y principios de los 90's. Luego, pasé directamente al proceso del movimiento del feminismo lesbiano, cuando me di cuenta que me gustaban las mujeres. Después de haber vivido en los Estados Unidos, a la vuelta, formé parte del activismo de lesbianas, estuve en la asociación de mujeres de la Universidad Complutense de Madrid. Formé la primera asociación LGBT universitaria que hubo en el Estado español. Mi formación viene del desarrollo comunitario. Así que mi primer interés siempre ha estado en el activismo. Claro, cuando llego a la universidad, ya tengo un porcentual potente. $Y$ los profesores universitarios me conocen como líder en organizaciones. No es más tarde, hasta que termino la universidad, y me voy a trabajar, que siento la necesidad de volver a estudiar. Y cuando estoy haciendo el doctorado me ofrecen un trabajo para estar en la universidad, para estar dentro de la universidad.

Rosa Blanca: ¿Porque has decidido volver a estudiar? Raquel Platero: En el activismo, no puedes hacer solamente cosas por hacer, deben tener un sentido. En ese buscar sentido a lo que haces, necesitas pensar, necesitas leer. Mi primera investigación fue la calidad de vida y las capacidades de escritoras de las mujeres con sordera. $Y$ fue una experiencia estupenda, porque mis padres son sordos, y yo hablo la lengua de signos casi como si fuera la primera lengua. Para mi es algo importante, el darse cuenta que tienes que estudiar, y no solamente que puedes trabajar por la gente, sino saber lo que estás haciendo.

En la Complutense, trabajo y academia encaja muy bien. Poder llevar de alguna manera lo que yo hago en el activismo a la academia, y viceversa, que la academia se interese también por el activismo. Es una buena combinación. Y yo lo noto. Tengo compañeras en la universidad que son puramente académicas. Su visión del mundo es un poco distinta, es puramente académica. Necesitas tener los pies en la tierra. Me parece importante no despistarse de la realidad de las personas.

Rosa Blanca: ¿La academia permite que tengas una práctica política?

Raquel Platero: No lo anima, no lo fomenta y no te ayuda nada a hacerlo. La academia exige monogamia. La academia exige que estés trabajando para ellos. Tienes que ser tú que tengas una agenda importante que te deje espacio para hacer cosas. Tengo mis propios contactos, mis propias actividades, y además mi trabajo que hago en la universidad, mi propio tiempo. 
' Elina NORANDI, 2009.

${ }^{2}$ Trujillo GRACIA, 2009

3 Raquel PLATERO MÉNDEZ 2008.

${ }^{4}$ PLATERO MÉNDEZ y Emilio GÓMEZ CETO, 2007

${ }^{5}$ Angie SIMONIS, 2007
Nunca he renunciado a ello, a mi activismo. Cuando hice la entrevista para trabajar en la universidad, en el año de 2003 , dejé claro que no renunciaría al activismo. No sabia hasta qué punto seria importante para mi vida, lo cuanto tendría que luchar para tener mis propios espacios, para mis propios libros que, también son académicos, pero se percibe que algunos libros como son más de sexualidad son considerados menos académicos que otros, que los que son sobre ciencias políticas, etc. Tienes que tener seguridad personal en el momento de tener iniciativa, y lanzarte, si no, la academia te dice que tienes demasiados intereses... En ese sentido, son bastante negativos.

Rosa Blanca: Haciendo un balance, ¿cuáles han sido las ventajas?

Raquel Platero: Muchísimas, desde cuestiones absolutamente personales como la capacidad de hablar en público, de saber con quién tienes que hablar para hacer acciones determinadas, tener cierta capacidad organizativa. Son cosas que traigo del activismo, que personalmente y egoístamente me hacen mejor para la academia, se me da bien dar la clase, porque se me da bien trabajar en grupos. Eso viene del activismo. Como también conocer gente desfalcada, pero que son personas claves en el momento de investigar.

Rosa Blanca: ¿Podemos hablar, en España, en la academia, de un campo de Estudios Lésbico-Feministas?

Raquel Platero: Yo lo veo pretencioso. Sí que hay gente estudiando lesbianismo desde la perspectiva feminista, pero es muy reciente, desde los últimos cinco años, pero no mucho antes. Ahora mismo hay una eclosión editorial de toda la gente que lleva un tiempo trabajando. Todas nosotras tenemos un trabajo, te pagan para hacer una cosa, pero decides y consigues hacer otras. Gente que se ha esforzado para entrar a la academia. Estoy pensando en Elinda Norandi que tiene una tesis sobre arte, pero tiene interés en el lesbianismo y en el feminismo: Ellas $y$ nosotras. Estudios lesbianos sobre literatura escrita en castellano.' Gracia Trujillo tiene una tesis sobre lesbianas, pero que ella enseña sociología sobre la educación, y recientemente publicó Deseo y resistencia (1977) - Treinta años de movilización lesbiana. ${ }^{2}$ Yo trabajo ciudadanía intima, pero he sacado libros sobre lesbianismo: Lesbianas: Discursos y Representaciones ${ }^{3}$ y Herramientas para combatir el bullying homofóbico; 4 este último en coautoría con Rosalía Aranda Redruello, Esther ColebrookNieto, J. Fernández-Rubio, y F. Mendoza. Angie Simonis aprovechó el trabajo de la investigación de la tesis, del Diploma de Estudios Avanzados (DEA): Yo no soy esa que tú imaginas; el lesbianismo en la narrativa española del siglo XX a través de sus estereotipos, y estuvo trabajando sobre lesbianas y literatura, y ahora ha publicado Cultura, Homosexualidad y Homofobia. ${ }^{5}$ María 
${ }^{6}$ Maria CASTREJÓN, 2008.

${ }^{7}$ Raquel OSBORNE, 2009.
Castrejón que tiene también otro libro sobre literatura y lesbianas: ...que me estoy muriendo de agua. Guía de narrativa lésbica española. ${ }^{6}$ Somos personas que estábamos haciendo investigación, que hemos buscado tiempo para trabajar sobre lesbianismo, desde una mirada feminista. Ahora estamos viviendo un tiempo de bonanza. Es el momento ahora, de que después de hacer todo un esfuerzo para entrar en la academia, de cómo pagar las facturas en el final de mes, que hayamos tenido un espacio para eso. Pero si hay algo como tú dices, un campo de estudios lésbico-feministas, es ahora, y no antes.

Eso no quiere decir que no haya gente como Raquel Osborne, autora de Apuntes sobre la Violencia de Género, ${ }^{7}$ que lleva muchísimo tiempo trabajando con el tema, que es una investigadora consolidada en la universidad, no sea ahora cuando se esté lanzando a hacer más cosas. El perfil de la gente que te he dicho antes es gente más joven, no senior.

Rosa Blanca: ¿Cuáles son los principales centros de investigación que tienen como foco los Estudios de Género, en España?

Raquel Platero: No necesariamente trabajan lesbianismo. Trabajan estudios de mujeres, y punto. Están desde los académicos en la Universidad Complutense de Madrid, como el Centro de Estudios Feministas Complutense; en la Universidad Autónoma de Madrid hay un Centro de Estudios Feministas que lleva tiempo trabajando. Está el Centre Dona i Literatura, en la Univeresitat de Barcelona, o el Duoda, Centro de Estudios sobre la Mujer. Está la Ezcal-Herrico Unibertsitatea que también tiene, con Arantxa Campos. Hay una buena profusión de programas de género.

Ahora, los masters han tenido que hacer una transición para ver si son masters oficiales o no. Algunos programas de género se caerán, porque no son tan buenos, otros permanecerán. Los Estudios de Género gozan de una buena salud. Están surgiendo en casi todas las universidades. Cuando la universidad es demasiado pequeña, lo que hace es un master intercampos, y se hace on line. Pero lo que no tienen es hablar sobre la sexualidad, sino vinculada a salud, como menopausia. No todos hablan sobre la construcción social de la sexualidad, o las cuestiones de sexualidad en grupos minoritarios. Y si lo hacen, lo efectúan como un tema menor. Yo enseño políticas públicas, pero aprovecho el estudio de las políticas publicas de igualdad para hablar de interseccionalidad: en qué forma la sexualidad aparece, desparece o está oculta, o sea, la interseccionalidad en esas políticas de la igualdad de género. El ámbito y tema de la sexualidad, a veces, está en manos de quien enseña, pero no en el currículo. En algunos problemas, la sexualidad sí tiene peso. Las alumnas quieren saber de teoría queer, y necesitan de alguien que les dé la mano. Parece que la teoría queer no tiene nada que ver con el feminismo, pero sí tiene que ver. Precisamos que el 


\footnotetext{
${ }^{8}$ Beatriz PRECIADO, 2008.

${ }^{9}$ Artista queer que ha llevado a cabo proyectos como The Ceremony London (1988) y The TransRangers (1999), entre otros.
}

currículo y la literatura académica nos acompañen. La gente tiene mucha curiosidad. Prueba de ello es que cuando hacen cursos de verano sobre sexualidad, la matrícula sube muchísimo. Estoy pensando en los cursos sobre sexualidad en la Universidad Internacional Menéndez Pelayo, en Santander, en el verano. Viaja gente desde cualquier parte de España para poder ir. Estamos todos como deseando aprender y discutir sobre sexualidad. Yo creo que para poder estudiar más sobre sexualidad desde una perspectiva queer, muchas veces no están siendo las universidades habituales como la Universidad Complutense de Madrid, o como la Universidad de Valencia, sino que son iniciativas como el FELGTB, o el Museu de Art Contemporani (MACBA), en Barcelona, con gente puntera tipo Beatriz Preciado ${ }^{8}$ que tiene una red. Ella trae gente extranjera como Del LaGrace Volcano, ${ }^{9}$ y desde ahí se hace una formación, y sin embargo, vuelvo a repetir, son museos a través de iniciativas que están surgiendo. Pero bueno, yo creo que estamos mejor que nunca, en el sentido que hacemos más cosas que nunca. Muchas veces tiene que ver con Barcelona, tiene que ver con cursos de verano, no tiene que ver con la formación habitual dentro de la carrera de todos los días. Profesoras y profesores hacen cosas sin que tú sepas. Por ejemplo, en la Universidad Juan Carlos I de Madrid, por ejemplo, hay una psicóloga que enseña en enfermería, habla del dolor para enfermeras, y para abordar el dolor, de la relatividad del dolor, habla del BDSM: bondad, dominación y sado-masoquismo. Y eso no aparece en el programa, y eso es hablar de sexualidad. En Psicología del Consumo, hablan del Mercado Rosa, del consumo gay, sucede en aula, porque hay gente que sabe, que tiene una mirada integradora y feminista, es una practica cotidiana.

Rosa Blanca: ¿Qué pasa con los Estudios de Género que ya están consolidados, no producen un tipo de desdoblamiento con cuestiones de sexualidad?

Raquel Platero: Mucha de la gente que dirige los centros de Estudios de Género no piensa que la sexualidad sea importante, sinceramente. Lo más importante que tienen es "Ia violencia contra mujeres". El master de Igualdad y Feminismo u otros masters específicos se preocupan en preparar expertas en intervención, etc. Pero solamente el tema de la violencia de género es el tema que verdaderamente es más importante, por la gama social que genera, y por los contenidos que han surgido. No hay masters sobre sexualidad, hay de sexología, o los ha habido en el pasado, pero no hay desde la universidad con la potencia que podrían tener.

Rosa Blanca: En el contexto de la Unión Europea, el Tratado de Ámsterdam de 1997 ya previa la importancia de la lgualdad de Género para políticas de ciencia, empleo/trabajo y educa- 
10 Maria BUSTELO RUESTA 2004. ción. Como integrante del proyecto MAGEEQ, ¿puedes explicarnos cómo nació ese proyecto?, ¿existió algún tipo de institución específica que haya tenido la iniciativa?

Raquel Platero: Es un proyecto europeo en el que trabajábamos seis países: los de norte y los del sur, y los que eran candidatos a la Unión Europea en su momento. Era un proyecto financiado por el Cuarto Programa Marco de Financiación de la Unión Europea. Funcionamos desde el ano 2003 hasta mediados de 2005.

Después, desde 2006 entramos en otro proyecto, en el Quality in Gender + Equality Policies (QUING), que significa la Calidad de las Políticas de Igualdad y Otras. Y ese "y Otras" es donde operamos con esa interseccionalidad. Es continuación del proyecto anterior. En el anterior estudiábamos países del norte y del sur y los candidatos, ahora estudiamos todos los países de la Unión Europea. Hacemos un estudio comparado, aunque es un estudio más de tipo cualitativo. Nos enfocamos en lo que está pasando con las Políticas de Igualdad, sus inconsistencias en su diseño, no nos interesa tanto la implementación. En MAGEEQ investigamos participación política, conciliación, violencia contra mujeres y derechos de gays y lesbianas.

En QUING, estudiamos más ciudadanía intima -que es en lo que me he especializado-, la maquinaria de las políticas de igualdad, la violencia contra mujeres y el no-empleo, que no es el mismo que el desempleo, que tiene que ver con tu filiación, con la organización familiar. Hay otras ramas que estudian manifiestos del movimiento feminista, por ejemplo.

Otra parte del proyecto trabaja la formación en género $y$, a veces, sobre sexualidad.

Nuestra directora es María Bustelo. ${ }^{10}$ Ella es la investigadora principal del equipo español. Igual que hay investigadoras del resto de los países europeos que estamos investigando. Por ejemplo, en España, estaba el equipo que estudiaba Portugal e ltalia, viviendo aquí, trabajando desde aquí lo de sus países, viajando ocasionalmente para hacer entrevistas. El equipo español lidera también el proyecto que tiene que ver con la Formación de Género.

Rosa Blanca: ¿Esa noción de "igualdad" viene de alguna filosofía?

Raquel Platero: Justamente eso es lo que más nos interesa. Lo que tienen en común MAGEEQ e QUING es la problemática de la noción de igualdad. Lo que nos intereresaba, más que la definición de igualdad, era ver por qué había inconsistencias en las Políticas de Igualdad.

"Igualdad" parece una palabra sencilla, aparentemente parece que hay un consenso previo sobre lo que significa. Pero a la hora de trabajar y diseñar políticas públicas, resulta que es una palabra polisémica, cuando además contiene 
diferentes formas de pensamiento, desde cómo enfocar el trabajo, precisamente, por eso genera inconsistencias. Esa era una de nuestras hipótesis de base. Lo que nos interesaba era cómo mostrar las inconsistencias: ¿es una igualdad a los hombres?, ¿entre hombres y mujeres?, ¿qué tiene que ver con ciertas mujeres y no otras? ¿Políticas diseñadas para una mujer heterosexual, casada y trabajadora, y que apenas están diseñadas para excluir el resto? Porque de hecho lo hacen. Ese es mi trabajo: si las Políticas de Igualdad están excluyendo a lesbianas.

Rosa Blanca: El proyecto MAGEEQ pretende la re-inclusión de ciudadanos. ¿Cómo pueden ser incluidos como ciudadanos sin ser ciudadanos?

Raquel Platero: Parto de la idea de que las Políticas de Igualdad no son neutrales. Es algo sencillo, mucha gente lo sabe, pero hay gente que se resiste a pensarlo. Las Políticas Públicas para toda la ciudadanía no están pensadas para excluir, ni para fastidiar, ni hacer mal a nadie, en realidad sí lo hacen.

Por ejemplo, la ley del matrimonio entre personas del mismo sexo se aprueba en España en 2005. En realidad, es una ley que está pensada para compensar, que en toda su retórica y en todo el debate parlamentario se habla de la exclusión sexual tradicional en el estado español. Como hemos salido de una dictadura franquista que perseguía a la homosexualidad que era un delito, ahora es el momento de compensar y de darles a todos los mismos derechos, para traer ciudadanía plena. Cuando la ley se aprueba y, se va a ampliar, aparecen los problemas. La ley no ha tenido en cuenta que algunos ciudadanos puedan ser de otros países, por ejemplo. Justo se aprueba el matrimonio, justo se quiere casar una mujer de Barcelona con una de Argentina, y la persona que le ha tocado casarlas denuncia la situación. Y el juez dice que ese matrimonio no está reconocido en Argentina. Hubo otra situación similar. El argumento era el mismo: el país de origen del conjugue extranjero no permitía el matrimonio. Lo cual es absurdo porque el matrimonio es válido en España. Esto no sucede con el caso de Malta. En Malta, no existe el divorcio, y aquí, nadie se opone a que se divorcie alguna persona que sea de Malta. Lo que hay es una objeción de consciencia sexual que está impidiendo esto.

Al principio hubo esa incertidumbre, porque la ley no tenía un párrafo específico que reforzara la idea, haciendo referencia al país de origen, a la nacionalidad. Como la ley no decía nada, dejaba sitio para que toda la gente que tenía prejuicios, y que no quería aplicar la ley del matrimonio - que no es una ley, sino que modifica el Código Civil -, al no articular provisiones especiales, la gente se quedaba con el status quo, con lo que hay en la sociedad, y lo que hay en la sociedad es discriminatorio.

En el caso de mujeres, queda muy clara la filiación. En un matrimonio heterosexual, si hay un hijo, el padre no tiene 
que dar explicaciones si el hijo es suyo o no es suyo, nadie te pide una prueba, nadie te pide una prueba de ADN.

En el caso de lesbianas, en el primer momento de aplicación de la ley, no hubo reconocimiento de filiación automática. Se tuvo que iniciar un proceso de adopción mutua. Por ejemplo, Ferrín Calamita es un juez que tuvo problemas, porque empezó a decir que eso no debería ser así, que el padre biológico de las niñas debería tener derecho a tener a sus hijas, de lo contrario, íbamos a estar produciendo una fábrica de lesbianas y eso sería terrible para la sociedad.

Cuando hay margen para la interpretación, es porque la ley no es suficientemente clara. Y eso pasa porque se parte del principio de que la ley es neutral, de que todos los ciudadanos son los mismos, y todas las ciudadanas son las mismas. Esto lo hemos aprendido con el feminismo, con la perspectiva de género: esa ley tiene que articular acciones positivas. Esa ley no articulaba acciones positivas, pretendía que todos fuéramos iguales. Si de partida el sujeto homosexual lesbiano es desigual, tienes que articular acciones positivas.

Rosa Blanca: España está dividida en Comunidades Autónomas, configuradas cultural y territorialmente, lo cual indica que existe un tipo de descentralización política, con amplio poder administrativo y legislativo. ¿La constitución de Comunidades Autónomas en España, en lo que concierne a la elaboración de políticas públicas, ha favorecido la implantación de derechos LGTB?

Raquel Platero: Sin duda, en España estamos en un Estado cuasi federal, entonces surgen los problemas de la Autonomía de Catalunya y el País Vasco, que es un tema muy controvertido. Se supone una transferencia de competencias a las unidades autónomas. Pero podemos ver que en esas Comunidades, la igualdad no es amenazante. Cada Comunidad ha desarrollado las Políticas de Igualdad como le ha parecido. Y el "como le ha parecido", tiene que ver con su cultura sociopolítica, cuál es el grado de activismo de movimiento feminista y gay, cuáles son las fuerzas políicas, si hay necesidad de hacer acuerdos políicos con otras fuerzas porque no hay un partido que tenga toda la fuerza, hasta qué punto es una sociedad conservadora o no, cuánto de inspiración europea, cuánto de activismo con líderes fuertes. Son factores que hacen que surjan Comunidades Autónomas con cultura política. Clarísimamente, Catalunya y el País Vasco son dos sitios donde se han dado esas situaciones. La permeabilidad entre la sociedad civil y la política, es decir, el tránsito de la buena gobernanza se está produciendo, entonces no es casualidad que la ley de igualdad más progresista que tenemos en el estado español sea vasca, que permite que haya un partido sólo de mujeres, cosa que en el resto de España no sucede: no más de tantas mujeres, no menos de tantos hombres, y viceversa. 
"Chueca es un barrio localizado entre el Paseo de Recoletos, al este, y la Calle Fuencarral, al oeste, teniendo como epicentro la Plaza Chueca, en la ciudad de Madrid. En Chueca, se han establecido negocios de entretenimiento, diversión y consumo trans, queer, lesbiano, gay, etc., a partir de los años 90 .
Catalunya tiene un clima de diversidad política y de cultura políica alta, que permite un movimiento gay mucho más diverso que en ningún otro lugar del Estado. Genera tensión y problemas, pero también genera discursos posibles y una movilización, que hace que las políticas de la Generalitat tengan una riqueza, generen programas sociales que no surgen en otro sitio, que suponen un meanstream de la sexualidad que no sucede en ningún sitio, es una situación pionera a nivel europeo.

Rosa Blanca: ¿Quiere decir que no es el consenso de la formación de la Unión Europea lo que ha llevado a esas Comunidades Autónomas a pensar esas leyes de igualdad, sino que responde más al desarrollo de una cultura política? Raquel Platero: Son ambas cosas. Que España fuera parte de la Unión Europea es muy importante. El Estado Español se ha formado con gente que hemos estado en la dictadura. Tenemos una especie de complejo de inferioridad, tenemos siempre un deseo de formar parte de los países donde se toman las decisiones importantes. Tenemos esa idea de como pasado colonial, de país atrasado, franquista, absolutamente retrógrada, en el que no había industria, no había ciencia, no había conocimiento y no había progreso. Y siempre hemos mirado a Europa con ansia, con ansia de ser como los demás. Yo creo que la entrada a la Unión Europea encaja muy bien con ese deseo de progreso. Si te das cuenta, entre todas las Comunidades Autónomas hay un deseo de modernidad. Hay una gran influencia europea que legitima muchos de los discursos de lo que se está diciendo aquí, entonces, si la Unión Europea dice que hay que implementar una directiva, esa es una razón para ponerse a hacerlo. Esos intereses han encajado muy bien con la necesidad de progresar, de tener un papel visible. Existe un deseo de las Comunidades Autónomas de distinguirse unas de las otras, de ser muy europeas, deseo de modernidad y progreso, sabiéndonos un país retrasado. Tenemos un deseo ferviente de ser europeos.

Rosa Blanca: Has estado en otros países europeos, ¿cómo es ese progresismo, o esa idea de igualdad que la Unión Europea habla?, ¿de alguna manera se refleja en la vida cotidiana? Raquel Platero: Si y no. Ellas y ellos tienen derecho a hacer cosas. En Inglaterra y otros países, puedes adoptar sin casar. Ahora puedes casarte sin adoptar. Son derechos por separado. Hay derechos que ellas han conseguido antes: las políticas de la igualdad. Hay mucha cultura política, derechos sobre mujeres...

Curiosamente, en España, en lo que se refiere a los derechos LGTB, en lo cotidiano, hemos llegado a un nivel de visibilidad bastante alto, que no siempre corresponde con el nivel de homofobia que tenemos. Por ejemplo, el efecto Chueca: 11 beber cerveza a los ojos del mundo. Mientras que en otros lugares de Europa la gente se reúne a tomar cerveza a 
puertas cerradas, a puertas cerradas quiere decir que para estar en el local te tienen que ver y te ves.

Aquí vivimos más en la calle, tenemos otro clima, de pronto parece que hay visibilidad con los afectos. Eso no quiere decir que no hay homofobia, que la gente no se lo pase mal. Desde que se aprobó el matrimonio, la homofobia se ha disparado, y tenemos problemas en muchísimos sitios, los medios de comunicación, por fin, lo están mostrando.

España es un sitio de paradojas: hay visibilidad en la calle, pero hay quien despide homosexuales en el trabajo. Este año, dos enfermeros fueron despedidos por ser portadores IVH. El juez le ha dado la razón a la clínica donde trabajaban.

Comparado con otros países europeos, la verdad es que el matrimonio entre homosexuales aparece como la vanguardia de los derechos de las minorías sexuales. Y sin embargo, yo creo que la homofobia es el núcleo de los problemas, es algo que tenemos que abordar. A mí no me parece mal que la gente se pueda casar. El problema es que hay gente que tiene una mirada triunfalista, cree que el matrimonio es la última frontera. Yo no estaría de acuerdo.

Rosa Blanca: En tu artículo Intersecting Gender and Sexual Orientation: An Analysis of Sexuality and Citizenship in Gender Equality Policies in Spain, ${ }^{12}$ explicas todas y cada una de las leyes implantadas en cada Comunidad Autónoma. ¿Cómo es posible que el País Vasco haya elaborado leyes (la Ley 4/2005) que se refiere a la "múltiple discriminación" que incluye raza, etnia, lengua, orientación sexual, etc., cuando en términos laborales es casi imposible la contratación de inmigrantes novascos?

Raquel Platero: Para ser funcionario en la administración pública tienes que hablar euskera, es difícil, porque no es una lengua de raíz latina. El euskera no se aprende fácilmente, no si no lo estudias. Tú sabes que el euskera fue prohibido por Franco. Existe una revalorización del euskera. Ahora ha habido un cambio de política con la coalición del Partido Popular (PP) y los socialistas, y están echando para atrás una serie de medidas proteccionistas con el euskera. Yo no sé que nos queda por delante.

Rosa Blanca: Un otro objetivo del proyecto MAGEEQ es favorecer el desarrollo de Estudios de Género. ¿Cuáles son las medidas que ha tomado el Ministerio de Educación, Ciencia y Tecnología, para el fortalecimiento de los Estudios de Género en la academia española?

Raquel Platero: Nosotros hacemos análisis de políticas públicas, políticas de igualdad. Aquí existe el Ministerio de lgualdad. No estudiamos las políticas de educación. Tenemos que ver que es una heterogeneidad enorme. En Andalucía se han introducido agentes de igualdad en las escuelas, es pionera. La 
Ley de Igualdad Andaluza habla de homosexualidad también, de una necesidad de abordar lo afectivo sexual en la escuela. Algunas leyes hablan de la salud y no de la educación, otras de educación y no de salud. Es que en esa heterogeneidad de políticas de igualdad es que cada Comunidad Autónoma hace un poco lo que quiere. Sí que hay dinámicas de mimetismo, se copian unas a las otras, existe esa tendencia.

Rosa Blanca: ¿La estructura curricular en la secundaria contempla este objetivo?, ¿existe un régimen de políticas públicas educativas en España articulado con la lgualdad de Género propuesto por el MAGEEQ?

Raquel Platero: La Ley de Educación que está aprobada ahora, en el prólogo, habla de la educación afectivo-sexual, y habla de homosexualidad, y habla de diversidad. El problema es que solamente lo hace en el prólogo, cuando llega a los artículos no vuelve a aparecer, luego, se queda un poco en el aire, te permite, te da cierto pie, pero luego no termina de atar. Ahora mismo, se ha aprobado una ley que ha pasado por el Parlamento, imagino que irá al Senado y luego volverá, es el proyecto de ley que habla del aborto. Ese proyecto habla de educación sexual. Es otra manera de entrar en el tema de la sexualidad en las escuelas. La sexualidad es una cuestión amplia, globalizada, que se tiene que abordar desde diferentes sitios. Nos da una puerta, nos da legitimidad. En la educación trabajamos diferentes profesionales, y luego las competencias están transferidas a cada Comunidad Autónoma, donde cada realidad es distinta.

Rosa Blanca: El concepto de interseccionalidad en políticas públicas tiene mucho que ver contigo.

Raquel Platero: Es un tema que me interesa: la interseccionalidad. Hay intentos de comprender que las personas no somos solamente hombres o mujeres, sino que somos más cosas al mismo tiempo, y que eso tiene que ver con las circunstancias de tu vida. Es una mirada compleja, pero se entiende como doble discriminación, no como interseccionalidad. Se entiende interseccionalidad como fuente de exclusión social, como algo negativo, y no como una fuente de riqueza, de diversidad, como una manera de generar estrategias para todo el mundo a la hora de enfrentarse a problemas.

El concepto de interseccionalidad me fascina, yo lo conocí cuando ya estaba trabajando en ella sin saberlo. Mi primera investigación tiene que ver con mujeres con sordera, en la Comunidad de Madrid. Estudiábamos que eran capaces de leer y escribir, y que eso afectaba a su calidad de vida, y a su identidad, y a su lengua de signos. Es un ejemplo claro de que no puedes separar el hecho de que eran mujeres y de que eran sordas. Diferente de la situación de hombres, o sea, la 


\author{
13 PLATERO MÉNDEZ, 2007. \\ ${ }^{14}$ Rosalía Aranda REDRUELLO, \\ Esther COLEBROOK-NIETO; J. \\ FERNÁNDEZ-RUBIO; y PLATERO \\ MÉNDEZ, 2003 \\ 15 PLATERO MÉNDEZ, 2004 \\ 16 ARANDA REDRUELLO Y \\ PLATERO MÉNDEZ, 2003.
}

situación de hombres sordos es muy diferente a la situación de mujeres sordas. Es una cuestión de partida y de socialización de género. Mis trabajos en ese campo son: Mujeres y sordera; ${ }^{13}$ Las mujeres sordas: formación y posibilidades, ${ }^{14}$ en coautoría con Rosalía Aranda Redruello, Esther Colebrook-Nieto, y J. Fernández-Rubio; Mujeres discapacitadas y malos $\operatorname{tratos}^{15}$ y Las habilidades Lectoescritoras como Facilitadoras de la Inserción Laboral de las Mujeres Sordas. ${ }^{16}$

Luego, trabajando en la universidad todo lo que tiene que ver con el lesbianismo, cómo las políticas de igualdad incluían o excluían a lesbianas, de nuevo aparece un interés por "doble discriminación". Cuando llegué al concepto de interseccionalidad me fascinó, porque explicaba mucho, no era solamente sumar. Ya no era solamente sumar lo que tú tenías como lesbiana con lo que tenías como mujer, sino que justamente la situación específica de lesbianas, negras, gitanas o sordas, te daba mucha información sobre otras categorías de exclusión social, de pronto cuánto de importante es la clase social, de pronto cuánto de importante es estar en un espacio urbano y no rural. En ese sentido, los efectos que tiene una situación estructural de desigualdad con otra no son sumativos, son exponenciales. Sordera más mujeres es igual a dos, a dupla discriminación, no, no (!), no es un tipo de discriminación con otro. No es uno más uno. Es como tres elevado al cuadrado (!) En ese sentido, cuando estudiaba mujeres sordas, la situación de la clase social no sabía como articularla. Esa mirada de doble discriminación no me servía para nada. La mirada de interseccionalidad es más compleja. Hay gente que tiene resistencia a entenderla, porque es bastante potente. Para mucha gente les parece nuevo. Se lleva trabajando desde los años 60 y 70, desde la teoría feminista. Ahora me estoy centrando en mi tesis, y también preparo un proyecto de libro que trabajo con un grupo de personas, donde estudiamos la interseccionalidad desde una perspectiva queer, para entender la diversidad sexual y problemas que surgen en el estado español. Trabajo la interseccionalidad en la agenda política española, y sobre todo el tema de ciudadanía íntima. Están Elin Peterson y Silva López que, estudian la interseccionalidad en el ámbito de la violencia y el no-empleo.

Rosa Blanca: En Octubre de 1983, el PSOE apoyó la creación del Instituto de la Mujer, una agencia nacional dependiente del Ministerio de la Igualdad, que funciona mediante la Secretaria General de Políticas de la Igualdad, con el objetivo de fomentar la implantación de políticas de igualdad de sexos. En ese sentido, ¿la construcción de un marco político por parte del PSOE para la actuación de mujeres, a través del Instituto de la Mujer, ha favorecido la obtención de derechos LGBT? Raquel Platero: Las Políticas de Igualdad de España se dice que comienzan en el año 1983, esa es la fecha que explican 

esto.

La creación del Instituto de la Mujer tiene que ver con un seminario que se hizo dentro del propio grupo socialista de trabajo en el que se estaba hablando sobre la relevancia de las Políticas de Igualdad, en el contexto previo a la entrada a la Unión Europea. Pero España ya se está mirando en Europa, está viendo que existen otras instituciones de género en otros países europeos. Es un mimetismo, es una manera de mostrar progreso. El Instituto tiene un rango interesante porque posee independencia administrativa, aunque está suscrito en su momento al Ministerio de Asuntos Sociales.

Cuando hay las elecciones, el PP dice clarísimamente que cuando entre en el poder va a quitar el Instituto de la Mujer porque es algo innecesario. ¿Qué pasa después? Que entramos en la Unión Europea, y el tema de la "igualdad" es importante. Y fondos estructurales de muchos millones de pesetas, y de euros después, se van a venir al Estado español. No tiene sentido desmantelar El Instituto de la Mujer. El gobierno del PP, cuando ha tenido en su cartera las Políiticas de Igualdad, lo que hace es una inversión descafeinada, o más amable, o más alrededor de la familia, de las mujeres rurales, por ejemplo, en Galicia, o en Madrid. Se va desapareciendo esa resistencia con eliminar esas Políticas de Igualdad, pero se van a convertir en algo menos transformador. Pero en la medida en que se establece una posición más fuerte en la Unión Europea, se produce esa transferencia de esas competencias a todas las comunidades. Ya no se hace viable cargarse esas Políticas de Igualdad, se produce un desarrollo heterogéneo. Poco a poco pasa a dejar de ser una cuestión secundaria o un poco molesta, en ese sentido, para irse convirtiendo cada vez más en una dimensión más relevante.

En esa trayectoria en el tiempo, en que estuvimos con el partido conservador, con el PP en el gobierno central, hay un relevo, se produce un giro cuando el PSOE vuelve a estar en el poder, y una de las primeras acciones es aprobar una ley integral contra la violencia, que viene de una demanda tradicional del movimiento feminista (!). No es exactamente la misma ley que estaba pidiendo el movimiento feminista, pero se aprueba esa ley que era largamente demandada por la sociedad civil. Se aprueba también una ley de matrimonio entre personas del mismo sexo, se reconoce la lengua de signos española y catalana como lenguas oficiales, se aprueba una ley sobre la dependencia, se aprueba una ley sobre los derechos de personas transexuales, se cambia la nomenclatura de personas minusválidas a discapacitadas. Cambios de lo qué significa una construcción de cierta igualdad.

¿Te acuerdas que me preguntabas sobre el proyecto MAGEEC y el estudio de la igualdad? Pues podemos observar esa igualdad en esas legislaturas socialistas, cómo ellos hacen 
de la igualdad un baluarte, una seña de identificación con su gobierno sobre todo con la legislatura anterior: 2004-2008. Es una legislatura que le llaman legislatura social, y que en el cambio, actualmente, tiene que ver con la crisis económica, con todo lo que tiene que ver con sistemas económicos, pero que en la anterior, lo que estaba haciendo es llevar muchas de las demandas que aparecen en la sociedad civil, en los movimientos civiles, a la agenda principal y que construyen una cierta idea de lo que es la igualdad. Es lo que permite vernos como un país moderno. Nos interesaba la idea de progreso y cambio, que puedes hacer frases como "España y Suecia", antes impensables. Nos genera complacencia, nos sentimos bien siendo un país moderno. Incluso los que se sienten mal se sienten bien: la iglesia católica y el Partido Popular tienen varios temas alrededor del cual generan movilización. Viene muy bien tener en la agenda un tema controvertido, porque así todo el mundo puede ser blanco o negro. El PP puede estar en contra del aborto, pero aunque esté en contra, genera mucho rendimiento políico. Los que están a favor son los que traen libertad, son los que consiguen, se presentan así mismos como progresistas. Los que están en contra generan movilización. Son temas que polarizan el debate y todo el mundo sale reforzado. Son temas altamente rentables.

Rosa Blanca: En el mismo artículo Intersecting Gender and Sexual Orientation: An Analysis of Sexuality and Citizenship in Gender Equality Policies in Spain, hablas de un sujeto político gay, ¿podríamos discutir de la misma manera una sujeto político lesbiana?

Raquel Platero: Ojalá. Ahora mismo estamos en un momento de profusión, de gran generosidad, estamos teniendo más movimiento que antes. Acabamos de pasar por unas Jornadas Feministas Estatales con 4 mil mujeres, y algunos hombres. Estamos empezando a tener otros foros: Barcelona y el País Vasco, un poco Madrid, que están generando espacios para hablar de política, de sexualidad. Hay autoras claves, hay una profusión de nuevos textos en el mercado: Literatura Queer, Literatura Feminista, generando una masa crítica.

No lo sé si hay un sujeto político lesbiano. Me darían ganas de decirte que sí, pero tengo que ser justa y decirte que ojalá. Porque tengo muy claro que es necesario que esa sujeto político lesbiana esté articulada. Y, por supuesto que hay lesbianas, por supuesto que hay activismo, hay voces importantes, pero esa sujeto político lesbiana no sé cuánto está articulada, no se cuánto se podría decir si las asociaciones de lesbianas están teniendo una consciencia realmente política para presentarse a si mismas como un interlocutor en la sociedad.

La Federación Estatal de Lesbianas, Gays, Transexuales y Bisexuales (FELGTB) ha tenido varias crisis. Acaba de tener un congreso en Gijón. Ha trabajado. Pero, ¿cuánto de representativo 
${ }^{18}$ Se refiere al creador de la revista electrónica queer: $<$ www.hartza.com $>$.

\footnotetext{
${ }^{19}$ Revista electrónica cuatrimestral de la Universidad Complutense de Madrid.
}

es esa entidad para con la gente que no está asociada, para lesbianas que están en la calle, gente más cotidiana? Pues no les llega, todavía no tiene la suficiente fuerza ni visibilidad en la calle, no tiene representatividad.

Sí es cuando tenemos más libros y voces públicas que nunca. Otra cosa es que no hay modelos. No podemos identificar mucha gente en la agenda cultural, social o política que hable de su lesbianismo públicamente, no sé cuánto son importantes nuestros libros de lesbianismo, nuestras actividades o nuestra visibilidad en un momento dado.

Rosa Blanca: En tus artículos veo que recurres a revistas electrónicas como Feminist Review, GLQ: A Journal of Lesbian, Gay and Queer Studies, European Journal of Women's Studies, Diagonal, Aequalitas, a documentos electrónicos como MAAGEQ Research Report, International Review of Modern Sociology, Feminist Legal Studies, etc. ¿Cómo tienes acceso a revistas electrónicas?

Raquel Platero: En mi caso es difícil. Accedo a través de una clave de una universidad de Holanda. Si estoy en la Complutense, pues la universidad paga algunas de las licencias para consultar algunas de las revistas electrónicas on line. Pero, mayormente, lo miro a través de mi clave de Holanda, o escribo a la persona que escribió el artículo para que me lo envíe, a veces lo hacen, a veces no lo dan. A mí mucha gente de América Latina y de España me pide mis artículos y se los doy, porque no puede acceder a revistas electrónicas.

No tengo derecho para distribuir mis propios artículos, de hecho hago trampa. Ahora se los he dado a Javier Saez ${ }^{18}$ para que los publique en su revista. La gente puede bajar mis artículos de la red y otros. Yo distribuyo los míos, porque cuando quiero tener acceso a otros no me resulta nada fácil, y si yo estoy dentro de la academia, imagina cómo será para otras personas que no lo están, o que están en universidades más pequeñas que la Complutense. No lo sé.

Rosa Blanca: En Brasil, el Ministerio de Educación y Ciencia (MEC) ha apoyado la creación de Scielo para dar visibilidad y divulgación a la investigación que se produce académica y científicamente en América Latina, facilitando la publicación en portugués y español. ¿Cuál es el portal que el Ministerio de Educación, Ciencia y Tecnología ha dispuesto para la visibilidad de sus investigadoras/es y para la divulgación de sus investigaciones españolas en la red?

Raquel Platero: Nosotras/os estamos rendidas/os al inglés. Es que de las revistas españolas hay muy pocas que puntúen internacionalmente. Hay varias revistas indexadas, por ejemplo: Política y Sociedad, ${ }^{19}$ y sin embargo no puntúan a nivel internacional. Entonces, la mayor parte de nosotras/os estamos 
${ }^{20}$ Revista electrónica: <www. arteypoliticasdeidentidad.org> ${ }^{21}$ Virginia VILLAPLANA, 2002. obligadas/os a publicar en inglés. Me interesa estar en las revistas extranjeras. He comenzado a publicar en castellano hasta hace poco. Primero publico en inglés en el extranjero y después en español, porque la mayoría de las/os españolas/os no lee en inglés. Claro, prefiero escribir en español, mil veces.

Consulto los artículos electrónicos porque mi tesis va a ser una de las primeras tesis en el departamento basadas en artículos publicados, y me piden que sea en revistas indexadas muy importantes.

Rosa Blanca: ¿Cuáles son las revistas electrónicas académicas especializadas en Estudios de Género, Lesbiano-Feministas o Queer en España, a parte de iniciativas "personales", como la de Javier Sáez?

Raquel Platero: Hay una revista nueva: Arte y Políticas de Identidad, ${ }^{20}$ en el comité está Virginia Villaplana, ${ }^{21}$ entre otras/ os profesionales, que aborda la sexualidad a través del arte.

Rosa Blanca: ¿Has observado algún cambio en tus investigaciones sobre Estudios de Género o Lesbiano-Feministas, a partir del momento en que has dispuesto de documentos Open Access? Raquel Platero: Realmente no puedo decir, porque hubo un tiempo que no tenía código para entrar, durante un tiempo usaba un código de Harvard, y luego ya menos. Es un fastidio, cuando quieres leer algo y no puedes. Estás investigando y te queda con peor calidad. Me da rabia, a veces no tengo disponibilidad. Me pongo a pensar que si estuviera trabajando en una universidad anglosajona, en Inglaterra, como Kent, o en los Estados Unidos, como Minnesota, esto no me pasaría. La calidad de mi trabajo se resiente de mi formación que es peor, se resiente de mi acceso a recursos que es peor, y se resiente de mi vida precaria que es peor. Para ser igual de bueno a alguien de fuera, tienes que ser tres veces más bueno, y quitarte de ese discurso exoticista, de que se diga que España es un país tan raro y católico, y de que además parece poco interesante para Europa. Son cosas con las que tienes que luchar.

Rosa Blanca: ¿La información que circula en la red también ha colaborado para una España preocupada con políticas de diversidad sexual?

Raquel Platero: Seguro. Brutal. Muchos de los libros los he puesto en Internet precisamente por eso. Los discursos viajan más rápido, discursos difíciles con temas complejos como la performatividad, o la interseccionalidad. Gracias a lo que lees de fuera, a las tra-ducciones que viajan como el rayo, hay más posibilidades. Me interesan los libros que están en Critic commons. Por ejemplo: Traficantes de Sueños, ${ }^{22}$ esos libros están disponibles en Internet, eso no hace que bajen las ventas. Libros que están disponibles, los puedes imprimir, pero 
${ }^{23}$ PLATERO MÉNDEZ, 2007.

${ }^{24} \mathrm{http}: / /$ www.rqtr.org. no vale la pena. La accesibilidad hace que la gente te pueda leer en Internet. Es maravilloso.

Hay fragmentos de la introducción de Lesbianas: Discursos y Representaciones que están accesibles en una revista mexicana, y se los he dado a una revista portuguesa para que esté dispuesta on-line.

Para la publicación Herramientas para combatir el bullying homofóbico, pedí a la editorial que pusiera gratis en la Web la introducción del libro. Las personas pueden conocer la obra y después comprar el libro. Un poco romper con la idea de la propiedad intelectual, con esa cosa de que tú no lo puedes tener. Al fin de cuentas, tú quieres que te lean. No todas las editoriales tienen la misma distribución. No todo el mundo puede comprarse un libro. Las mismas políticas de las revistas de investigación, no dejan colgar tus artículos. Yo puedo tener un problema legal, pero a mí me da igual, no me importa, yo lo pongo en la red, en todas partes. Es muy difícil escribir y que te lean. Yo escribo muy despacio, y además, tienen que editar mis textos. Tengo dislexia. Realmente trabajo mucho y quiero que la gente lo lea.

Rosa Blanca: En tu artículo Overcoming Brides and Grooms. The Representation of Lesbian and Gay Rights in Spain, ${ }^{23}$ analizas la representación de lesbianas y gays en políticas españolas, dentro de las políticas del Plan de lgualdad. ¿Ha habido un tipo de construcción de la imagen lesbiana para el fortalecimiento de sus derechos? Tú, como activista, ¿cómo participas en esa elaboración de imagen, de la visibilidad lesbiana?

Raquel Platero: Trabajo con la representación: cómo se han conformado ciertas ideas, de cómo tenían que ser las cosas, de cómo se han construido ciertas imágenes, de qué era el lesbianismo a lo largo del tiempo. No cómo tiene que ser, que a veces a través de mi crítica se puede analizar el problema de mis deseos. Representación tiene que ver con eso, desde diferentes perspectivas.

Pensábamos que la idea de visibilidad era una idea transformadora y fundamental, desde que formamos RQTR (Asociación de Lesbianas, Gays, Transexuales y Bisexuales de la Universidad Complutense de Madrid) ${ }^{24}$, en 1994, y desde que he empezado a escribir. Siempre he pensado lo importante que es el hecho de que la gente te vea, que el lesbianismo, que la transexualidad, que la homosexualidad, fuera patente, visible, encima de la mesa. Que solamente por hacerla visible se podría hacer un cambio social. Ya no tengo 20 anos, no estamos en el año 94. Tengo un pensamiento más complejo.

La visibilidad no es necesariamente productiva en todos los casos. Muchas de las representaciones del lesbianismo que hay son híper negativas. Tampoco me creo que esa frase con la 
${ }^{25}$ PLATERO MÉNDEZ, 2009b

${ }^{26}$ VON HENTING, Hans. La criminalidad de la mujer lésbica. Estudios de psicología criminal. Madrid: Espasa Calpe, 1975. que cerramos todas las investigaciones diciendo que: "Ia invisibilidad lésbica es un tema fundamental, que explica la mayoría de las cosas". Esa idea me parece nociva, porque con esa idea de la invisibilidad lo que hacemos muchas veces es desarticular ganas de hacer cosas.

Muchas personas que estaban estudiando gays, la homosexualidad masculina, están buscando lesbianas en el mismo sitio donde buscaban homosexualidad. Buscamos transexualidad donde buscamos homosexualidad. Eso tiene que ver con nuestra ignorancia como investigadoras/que con nuestro objeto de estudio.

Lo que ha existido es una mirada disidente sobre la identidad y sobre la sexualidad. Que a veces se ha llamado travestismo, que a veces se ha llamado masculinidad, o lo que quieras. Las identidades modernas no las podemos trasladar al pasado.

La invisibilidad lésbica ya no me parece explicatorio. Las sexualidades no-normativas son híper visibles, y esto es algo que he aprendido estudiando el franquismo, y que discuto en Lesboerotismo y la masculinidad de las mujeres en la España franquista. ${ }^{25}$

Todo el mundo dice, todos los autores y autoras: "durante el franquismo, la sexualidad de las mujeres se construía alrededor de la sexualidad de los hombres, los hombres eran activos y las mujeres eran pasivas, los hombres eran el trabajo, la fuerza y la sexualidad, y las mujeres eran la sumisión, el cuidado...". ¿Cómo es posible que se creen leyes específicas para reprimir la sexualidad, si la sexualidad no es algo que está patente en la sociedad? Si no hay un pánico sexual en una sociedad represora como la franquista que está notando que pierde el control sobre los ciudadanos, ¿por qué se hace una Ley de Peligrosidad y Rehabilitación Social en el año 70, cuando ya tenían una ley que reprimía la homosexualidad?

Te vas a los libros que escribían los jueces de la época, como Savater Tomás, que redactó la Ley de Peligrosidad y Rehabilitación Social en el año 70, y vas a percibir que él sabia de lesbianismo, se había leído el libro de Hans Von Henting, ${ }^{26}$ que había estudiado casos de criminales como las mujeres que vendían aguardiente en el Parque del Retiro de Madrid, que eran ladronas, lesbianas, criminales. Justamente estamos en un país en el que están estudiando Vallejo Nájera y López lbor, dos psiquiatras, que están justificando que existe un gen rojo, que son los que justifican que las mujeres son patológicas por naturaleza, que tienen cierta tendencia al lesbianismo, que son personas débiles, que son personas que tienen que estar sujetas por el Estado y, en su nombre, por el padre o por el marido.

Todavía hoy existe una clínica muy famosa donde están trabajando los familiares de los López lbor. Y a la gente se le ha olvidado que ellos ubicaban a los rojos, a los marxistas, como 
poseedores de un gen patológico, de una enfermedad mental. Han estado justificando la represión, desde la psiquiatría y psicología, son los que están a favor de los electroshocks, las lobotomías y la justificación ideológica represora de las sexualidades minoritarias, y la represión de mujeres en concreto. Es en ese sentido que afirmo que la invisibilidad de las lesbianas no existía. Cuando se habla que: "No había nadie como tú, muchas veces pensabas que eras la única", para los represores, para la administración pública, para la iglesia y para la psiquiatría, el lesbianismo sí exista. Yo no me creo esa invisibilidad, lo que creo es un trabajo consciente para ocultar para que tú no lo sepas. Pero los que tenían que saber sí lo sabían. La masculinidad de las mujeres supone una híper visibilidad, la mariquita, el afeminado, el travesti, son ejercicios de híper visibilidad.

Estamos errando nuestra mirada. Estaba oculto, estaba prohibido, era proscrito. Era difícil tener colegas. Pero sabemos de espacios de relación, sabemos que la gente se inventaba palabras en argot para conocerte, de lugares de ligue. Con lo cual la represión estaba siendo eficaz a la hora de controlar eso. Era una gran manera de hacer una política del silencio. Pero la sexualidad es híper visible.

En una sociedad de control social brutal, donde no te puedes mover sin que nadie pueda largar lo que has hecho, si eso se puede decir del franquismo, que es nuestra historia reciente más cercana, en el momento actual no podemos seguir hablando de invisibilidad. Lo que hay ahora es una dificultad para identificarse con una etiqueta "lesbiana", que a mucha gente no le sirve. Mucha gente ha crecido pensando que las feministas tienen muchos pelos en el sobaco, que las lesbianas son feas y que odian a los hombres. Ante ese monstruo feo, la gente no quiere ese monstruo feo. Muchas tías que tienen relaciones con mujeres durante casi toda su vida no se identifican con la palabra lesbiana. Por otra parte, está la gente más moderna, más joven, que tiene una influencia mas queer que está diciendo: "yo me niego a nombrarme, porque la etiqueta me queda pequeña, no quiero que la gente me señale con el dedo como lesbiana, porque yo soy más cosas que lesbiana". Entonces, por un lado, está toda esa gente afectada por su homofobia, por el otro, gente que se resiste al tema del etiquetamiento porque le parece demasiado constreñidor.

En medio, por decir de alguna manera, está esa gente que se considera dentro de la palabra lesbiana. La identidad lesbiana le da mucha fuerza, le da una cultura, le da un espacio de relación, le da acceso a revistas, a eventos culturales, a cosas que le puedan resultar relevantes.

Ahora, en el libro Lesbianas: Discursos y Representaciones, analizamos que no es tan productiva la identidad lesbiana como la identidad gay. No tiene los mismos beneficios. 
Y es como las cuestiones de género. La lesbofobia tiene elementos diferenciales con respecto a la homofobia. La frontera entre lesbianismo y la transexualidad no es nada clara, es bastante difusa. Hay una espacio de la masculinidad femenina, de la transexualidad masculina, del rollo andrógino, del rollo butch, del rollo trans, del rollo boy, que a mí me parece delicioso. Pero para la conformación de la identidad es un poco oleoso.

Rosa Blanca: En diciembre de 2009, el Ministerio de Cultura, dentro de la Ley de Economía Sustentable, ha estado amenazando con censurar la Web para impedir downlands de películas, libros, etc. Franco mantuvo películas enlatadas durante décadas. Toda la producción surrealista, por ejemplo, que data de principios de siglo XX, fue vista por las/os españolas/es hasta mucho después que murió Franco, mucho después de 1975...

Raquel Platero: No va a suceder. El Ministerio se ha echado para atrás. A los españoles nos gusta mucho eso de romper las normas. No somos como los anglosajones. Somos de una cultura distinta. Si podemos bajar películas de interés, lo hacemos. Los de la Sociedad General de Autores y Editores son abusadores, son abusivos en las prácticas que tienen. Para casi todos nosotras/os, como gente intelectual que producimos, como gente que escribimos, Internet es fundamental. Tienes que estar en Internet. Estoy haciendo bastante esfuerzo, el más grande, para que mis conferencias y mis artículos estén accesibles online. A mí me interesa mucho que la gente me pueda escuchar. Hacer accesible es lo importante.

Rosa Blanca: ¿Crees que el arte en la globalización, en la red, contribuye para la constitución de relaciones de identificación en términos de imágenes?

Raquel Platero: Sí, claro, todo el tema de la subcultura, la gente trans, las boyeras, estamos locas por tener referentes, tenemos verdadera hambre, de saber más, de ver. Si surge una película nueva, si la hay, corre como la pólvora. Y si estamos muy interesados o interesadas, significa que tenemos bastante necesidad. Cada vez que sale un libro o película sobre tema lésbico, o sobre o tema trans, lo celebramos como un verdadero éxito.

Rosa Blanca: ¿Puede hablarse de una estética queer española, a diferencia de la queer estadounidense, por ejemplo?

Raquel Platero: ¿De cultura visual?

Rosa Blanca: Sí.

Raquel Platero: Está habiendo un impacto de tipo narrativa, un tipo de escribir diferenciado. Estoy pensando en Paco

${ }^{27}$ Francisco VIDARTE, 2007

${ }^{28}$ Itziar ZIGAR, 2009. Vidarte, ${ }^{27}$ Beatriz Preciado, Itziar Ziga, ${ }^{28}$ etc. Ha estado surgiendo una manera de escribir más irreverente, más en lo personal, más en un lenguaje cotidiano, a veces muy académico, y al 
29 Judith HALBERSTAM, 1998.

${ }^{30}$ Judith BUTLER, 2007.
${ }^{31}$ PLATERO MÉNDEZ, 2009a. mismo tiempo muy vulgar, muy de la polla, de estoy hasta el coño, que está generando otra especie de discurso, como lo porno, lo postporno. Todo eso está abriendo o haciendo muchos espacios alternativos, más presente dentro de lo queer. Está habiendo un aprecio, una estética de aprecio al BDSM o a la postpornografía. Son actividades muy minoritarias, pero que cada vez comienza a haber en más sitios.

Dentro de la estética de lo queer está entrando lo postporno, está muy presente el oso, y también está presente la masculinidad femenina. Se trata de subculturas que pertenecen a cierta élite intelectual y activista. Actúan en grandes sitios como el MACBA, en Barcelona, o el Arteleku, en Donosti. Están viniendo de sitios absolutamente cutres y secundarios para entrar en espacios cada vez más de arte, de ciertas élites. Es fundamental que se mezcle la cultura feminista con lo queer, con lo postporno. Me parece algo delicioso, porque es algo que lees sobre Nueva York y sobre Londres, y que de alguna manera está sucediendo aquí. Tenemos mucha suerte, mucha gente de la más importante del mundo viene a España, tiene interés en venir a hablar. Ha estado Judith Halberstam ${ }^{29}$ y Judith Butler. $^{30}$

Rosa Blanca: ¿Crees que de alguna manera se ha disuelto la frontera entre arte y política a través de la estética queer, por ejemplo?

Raquel Platero: Sin duda. Hay consecuencias políticas. Está el trabajo de Beatriz Preciado, está la guerrilla en la calle: grupo de activistas transexuales y transgéneros, se rodean de gente que no es trans, que está metida en espacios de sociología, activismo y ciencia, son las personas que producen esos saltos, y que lo hacen en primera persona.

Rosa Blanca: ¿Crees que existe una articulación entre la estética visible y la práctica política? Me refiero a tu performance visual.

Raquel Platero: Yo no hablo sobre imagen, yo produzco esa imagen. Estoy saliendo del armario, estoy intentando encontrar un espacio como persona transgenérica. Autoras importantes exploran la masculinidad en cuerpos de biomujeres. Yo, sin ser artista o actor, soy parte de esa producción de imagen.

Soy portada de libro, produzco imagen. Eso encarna una serie de cuestiones, justamente porque soy en primera persona, lo que hace que las personas te escuchen.

Rosa Blanca: ¿Cómo ha afectado ese tipo de estética en tu investigación actual sobre ciudadanía íntima? Estoy hablando de tu investigación y reflexión en el artículo Transexualidad y agenda política: una historia de (dis)continuidades $y$ patologización. ${ }^{31}$ 
Raquel Platero: Estudio la masculinidad femenina en el franquismo, la transexualidad en el Estado español. Hago cuestiones y conexiones: el parentesco con las transformaciones del cuerpo, con derechos individuales y colectivos. Quién tiene derecho a ser ciudadano y quién no. Por ejemplo, para el aborto, no puedes decidir porque tienes 16 anos, o tienes que hacerlo sin decírselo a tus padres. Si eres un bebe intersexual, son tus padres los que deciden tu sexo. Investigo en qué momento puedes ser considerada persona. Pienso que no puedes decidir sobre la transexualidad, no puedes decidir para otras personas.

No te piden permiso cuando eres un bebe para modificar, para decidir tu cuerpo. Investigo derechos para decidir sobre tu cuerpo. Hay fronteras, me interesa mucho ese debate, de los derechos individuales y derechos colectivos, de la ley que permite cambiar el nombre en el registro civil. El DNI es una cuestión franquista para cuidar a los perdedores de guerra, prisioneros, etc. Es obligatorio, una medida de identificar, si eres hombre o mujer. Qué fastidio (!) No te puedes escapar de la foto o del nombre. Si lo haces, tienes un diagnóstico de disforia de género, un impacto psicológico. Me refiero a que, de todas las demandas, el colectivo transexual ha conseguido el cambio registral del nombre, después de un tratamiento psicológico de años, con disforia de género, para discriminar los verdaderos de los falsos. En Andalucía, hay un hospital que hace intervenciones de cambios de sexo.

Lo que todavía está ambiguo es quién tiene derecho, si eres ciudadano irregular, inmigrante, no se aplica, si eres menor de edad, o te diagnostican trastorno mental, tampoco. Resulta que las mujeres transexuales son discriminadas, comparadas con los hombres transexuales. ¿Quién te va a creer que te llamas Vanesa si tienes barba? Nadie te va a contratar.

Madrid, Diciembre de 2009.

\section{Referencias}

ARANDA REDRUELLO, Rosalía; COLEBROOK-NIETO Esther; FERNÁNDEZ-RUBIO J.; PLATERO MÉNDEZ, Raquel. Las Mujeres sordas: formación y posibilidades. Madrid: Instituto de Investigaciones Feministas de La UAM, 2003.

ARANDA REDRUELLO, Rosalía; PLATERO MÉNDEZ, Raquel. Las habilidades Lectoescritoras como Facilitadoras de la Inserción Laboral de las Mujeres Sordas. Comunicación y Publicación del I Congreso sobre Mujer y Discapacidad. Valencia, 2003.

. Las habilidades Lectoescritoras como Facilitadoras de la Inserción Laboral de las Mujeres Sordas. Comunicación y Publicación del I Congreso sobre Mujer y Discapacidad. Valencia, 2003. 
BUTLER, Judith. Vida precaria: el poder del duelo y la violencia. Buenos Aires: Paidos Iberica, 2007.

BUSTELO RUESTA, Maria. La evaluación de las políticas de género en España. Madrid: Catarata, 2004.

CASTREJÓN, Maria. ... que me estoy muriendo de agua. Guía de narrativa lésbica española. Barcelona/Madrid: Egales. 2008.

GRACIA, Trujillo. Deseo y resistencia (1977-2007: Treinta años de movilización lesbiana en el Estado español. Barcelona/ Madrid: Egales, 2009.

HALBERSTAM, Judith (Jack). Female Masculinity. USA: Duke University Press, 1998.

NORANDI, Elina. Ellas y nosotras: estudios lesbianos sobre literatura escrita en castellano. Barcelona / Madrid: Egales, 2009.

OSBORNE, Raquel. Apuntes sobre violencia de género. Barcelona: Bellatera, 2009.

PLATERO MÉNDEZ, Raquel; GÓMEZ CETO, Emilio. Herramientas para combatir el bulling homofóbico. Madrid: Talasa, 2007.

PLATERO MÉNDEZ, Raquel. "Intersecting Gender and Sexual Orientation: An Analysis of Sexuality and Citizen in Gender Equality Policies in Spain." Critical Review of International Social and Political Philosophy, v. 10, n. 4, p. 575-597, Dec. 2007. Routledge. University of Bristol Livrary. URL: http:// dx.doi.org/10.1080/13698230701660238.

"Mujeres Discapacitadas y malos tratos." Revista Perfiles, n. 180, p. 14-15, ONCE 2004.

"Overcoming Brides and Grooms. The Representation of Lesbian and Gay Rights in Spain." In: VERLOO, Mieke (Ed). Multiple Meanings of Gender Equality. A Critical Frame Analysis of Gender Policies in Europe. Central European University Press. Budapest/ New York, 2007.

. "Transexualidad y agenda política: una historia de (dis)continuidades y patologización." Revista Política y Sociedad, v. 46, n. 1 y 2, p. 107-128, 2009a.

"Lesboerotismo y la masculinidad de las mujeres en la España franquista." Bagoas, Revista de Estudos Gays, Gêneros e Sexualidades, Centro de Ciências Humanas, Letras e Artes de La Universidade Federal de Rio Grande do Norte, Brasil, $n$. 3, p. 15-38, 2009b.

PLATERO MÉNDEZ, Raquel (Coord.). Lesbianas. Discursos y representaciones en Madrid. Barcelona: Melusina, 2008.

PRECIADO, Beatriz. Testo Yonqui. Barcelona: Espasa, 2008.

SIMONIS, Angie. Cultura, Homosexualidad y Homofobia. Barcelona: Laertes, 2007.

TRAFICANTES DE SUEÑOS. Disponible en: <http:// www.traficantes.net>. Acceso en: 02 Jan. 2010.

VALIENTE, Celia. El feminismo de estado en España: El Instituto de la Mujer, 1983-1994. Madrid: Instituto Juan March de Estudios e Investigaciones, 1994. 
Políticas públicas de género en perspectiva comparada: Ia mujer trabajadora en Italia y España, 1990-1996. Madrid: Universidad Autónoma de Madrid, 1997.

VERLOO, Mieke (Ed.). Multiple Meanings of Gender Equality. A Critical Frame Analysis of Gender Policies in Europe. Central European University Press. Budapest/New York, 2007.

Disponible en: <http://www.rqtr.org > . Acceso en: 01 Jan. 2010. VIDARTE, Francisco J. Masculinitats per al segle XXI. Barcelona: CEDIC, 2007.

VILLAPLANA, Virginia. 24 Contratiempos. Valencia: Editorial De la Mirada, 2002.

VON HENTING, Hans. La criminalidad de la mujer lésbica. Estudios de psicología criminal. Madrid: Espasa Calpe, 1975.

ZIGAR, Itziar, Devenir Perra. Barcelona: Melusina, 2009. 